and Ericson and the recovery rate according to Okun), I and Diotallevi reported on the decrease of aqueous humour formation in diabetic patients. ${ }^{2}$ No difference was found between diabetics with and without retinopathy. In contrast, we found that insulin treatment was able to restore aqueous humour formation to normal values in diabetic patients, provided retinopathy had not yet been observed. Our findings suggested that the rate of aqueous flow is influenced by insulin treatment in diabetic patients, at least in the initial stages of the disease.

G AURICCHIO
Eye Clinic,
st Faculty of Medicine,
University of Naples,
Italy

1 Hayashi M, Yablonski ME, Boxrud C, Fong N, Berger C, Iovanovic LJ. Decreased formation of aqueous humour in insulin-dependent diabetic patients. Brf Ophthalmol 1989; 73: 621-3.

2 Auricchio G, Diotallevi M. Beziehungen zwischen Insulinbehandlung und Kammerwasserproduktion bei Diabetikern. Graefes Arch Clin Exp tion bei Diabetikern. Grae
Ophthalmol 1965; 168: 85-9.

SIR, - We appreciate Dr Auricchio's interest in and comments on our article. The suction cup method which Dr Auricchio used to measure aqueous humour formation is a pressuredependent technique and has several inherent problems similar to those of tonography. We believe that fluorophotometry is a much more accurate method of investigating aqueous humour dynamics. However, we regret that we did not refer to Dr Auricchio's paper, which also found a decrease in aqueous humour formation in diabetic patients.

MIEKO HAYASH MICHAEL E YABLONSK Department of Ophthlamology, 600 South 42nd Street Omaha, NE 68198-5540 $U S A$

\section{Bacillus-induced endophthalmitis}

SIR, - We regret that we incorrectly stated some antibiotic dosages in our article entitled 'Bacillus-induced endophthalmitis: new series of 10 cases and review of the literature' in the BFO 1990; 74: 26-9.

In Table II (p 27) the doses of 400 milligrams (mg) gentamicin (patients 5 and 8) are incorrect; the intravitreal dosage of gentamicin was 400 micrograms $(\mu \mathrm{g})$. The doses of clindamycin 1 gram $(\mathrm{g})$ in patients 5 and 8 are also incorrect; the dose was 1 milligram (mg). Finally, the vancomycin 1 gram (g) dosage for patient 8 is incorrect; the dosage was 1 milligram (mg)

ANN S BAKER RAMZI Harvard Medical School, Massachusetts Eye and Ear Infirmary, 243 Charles Street

Boston, MA 02114, USA

\section{BOOK REVIEWS}

Primary Angle Closure Glaucoma. By R F Lowe and A S M Lim. Pp. 89. No price given. PG Publishing: Singapore. 1989.

This slim volume distils the experiences of two eminent ophthalmologists in the diagnosis and management of angle closure glaucoma. The first eight chapters were written by Ron Lowe and reflect publications written by him on this subject dating from 1961 . The remaining four chapters were written by Arther Lim and describe his operative and laser techniques in the treatment of this condition.

Dr Lowe's contribution covers pathophysiology, clinical types, examination, and management. Each chapter carries many words of wisdom, as is to be expected from an ophthalmologist who has spent much of his professional career studying angle closure glaucoma. Each chapter concludes with references for further reading.

Dr Lim's contribution describes methods for the surgical and laser treatment of angle closure. He covers iridectomy (though the illustrations for this appear to be the same as, but smaller than those which appeared in his book Peripheral iridectomy, also published by PG Publications), trabeculectomy, including complications, and concludes with a small section on combined cataract and glaucoma.

The authors do not identify a readership. This reviewer also found it difficult to see whom the book was directed towards. The book is a simple and didactic description of angle closure glaucoma. It would be covered in content by more general ophthalmological texts. The illustrations have substantially been published elsewhere. The text is too simple and without adequate references for the specialist student of glaucoma. If a coffee table existed for ophthalmology textbooks, this one could be on it, but it need not grace the bookshelf.

\section{R HITCHINGS}

Synopsis of Ophthalmology. 6th Edn. By Jack J Kanski. Pp 237. £14.95. Butterworth: Sevenoaks, Kent, 1989.

Aids to Ophthalmology. By P T Khaw, D S Hughes, S J Keightley, R F Walters, A R Elkington. Pp. 294. £8.95. Churchill Livingstone: Edinburgh, 1989.

These two books cover similar subject matter so are reviewed together. Synopsis is a completely revised 6th edition, the previous edition having been originally published in 1975. Aids is a new book from a group of authors from Southampton Eye Hospital. Similarities between the books include their size, both being easily transported paperbacks, and intended audiences, in both cases ophthalmologists in training approaching their postgraduate examinations. They are also similar in use of shor note/list presentation rather than prose, and neither contains any illustrations or diagrams.

The subject matter in Kanski's book is systematic review of the main aspects of clinical ophthalmology, the chapter titles including eyelids, orbit, lacrimal apparatus, etc. Khaw and co-authors cover this ground but add more basic science material including optics and pharmacology, a detailed chapter on visual standards and a dedicated chapter on medical ophthalmology. Neither book can really be faulted for the accuracy of information presented. Interestingly, both books cover the difficult topic of nystagmus, but neither quite reaches the standard of the masterly chapter in Bajandas and Klein's Neuro-ophthalmology review manual (Slack, 1988).

The print is much tighter on the pages of the book by Khaw and co-authors and is therefore a much more daunting prospect than the spacious and concise layout of Kanski's book. The quantity of information in Aids is also much greater, and it has much more the feel of a condensed version of a textbook such as Newell's Ophthalmology: principles and concepts (Mosby, 1986). By contrast, Kanski sticks to mainstream clinical matters, which are covered in the neat way we have come to enjoy in his other books, including Clinical ophthalmology and The eye in systemic disease. The effect of these differences would be to make memorising the book by Khaw and co-authors a major challenge unless tackled with advanced examination preparations. Conversely, the moderately well read ophthalmologist in training could skim through Synopsis quite quickly and feel that new facts had been learnt on each page.

Both of these are good books and their authors are due great credit for the effort that their production must have involved. Aids to ophthalmology is packed with information and represents extremely good value for money. If I had to choose one to take on a desert island I would probably choose Synopsis because the delivery of information is so smooth.

Finally, I noticed that Duke-Elder's System of ophthalmology did not appear in the suggested reading at the end of Aids. I wonder if we could persuade the energetic authors of these two books to update the System of ophthalmology; this might once again mean that the definitive ophthalmic textbook came from the United Kingdom.

JOHN BRAZIER

Manual of Retinal Surgery. Edited by Andrew J Packer. Pp. 126. £29.95. Churchill Livingstone: Edinburgh. 1989.

This manual has been collected by a number of well-known American vitreoretinal surgeons. Nine chapters make up its contents, compressing much valuable information into a shor book. It forms an admirable way for a junior ophthalmologist to get a quick overview of the principles of an approach to a patient with retinal detachment. As always in a book of this size there is a challenge to the contributors to limit their comments to what they consider to be the most important topics. It was nice to see the chapter by Chang emphasising the need for careful preoperative examination and charting, though it had not occurred to me that the nasal periphery of the retina is easier to examine after indentation of the temporal periphery has softened the eye. There are useful comments on the use of preoperative ultrasound, and the chapter on prophylaxis poses the questions but is not strong enough on providing clear-cut guidance on the author's views as to when treatment should be recommended. The controversial topic of pneumatic retinopexy is included, and there is a welcome, but relatively long contribution on the anaesthesia for surgery. The section on scleral buckling surgery is full of useful practical information, but sadly the principles governing non-drainage retinal detachment surgery are poorly explained and some of the indications for encirclement (the treatment of aphakic retinal detachment) are contentious. It would also have been better if the principles of peroperative injection of air and the operative sequence necessary for its correct use had been clearly elucidated.

The chapter on posterior segment vitrectomy by Abraham is particularly effective. The length of this section reflects the increasing use of vitrectomy in modern vitreoretinal surgery. The author cleverly manages to incorporate a substantial degree of sophistication in the techniques that he describes. These techniques are of course well beyond the capabilities of those for whom this manual is intended, but it 